\title{
ESCOLHA PROFISSIONAL E DRAMÁTICA DO VIVER ADOLESCENTE
}

\author{
Maria Auxiliadora Barreto \\ Tania Aiello-Vaisberg \\ Pontifícia Universidade Católica de Campinas, Campinas, Brasil
}

\begin{abstract}
RESUMO: Este artigo, desdobramento de uma pesquisa mais ampla que focaliza o imaginário social sobre a adolescência contemporânea, investiga as concepções de estudantes de Psicologia e Pedagogia, futuros orientadores vocacionais, sobre o adolescente em vias de escolha da profissão. A pesquisa foi feita através do uso do Procedimento de DesenhosEstórias com Tema e a análise do material, baseada em conceitos blegerianos e num enfoque winnicottiano, revelou a existência dos seguintes campos psicológicos não conscientes: a dúvida, o desejo parental e a falta de confiança em si. Numa perspectiva psicoprofilática, o quadro geral indica a necessidade de reabilitar o adolescente na reapropriação de seu destino, uma vez que a dúvida constante aparece como resultado do não poder confiar em suas próprias capacidades nem nas capacidades decisórias dos pais, resultado das diversas modificações sofridas pela sociedade na qual estão inseridos.
\end{abstract}

PALAVRAS-CHAVE: adolescência; imaginário social; orientação vocacional; psicanálise; trabalho.

\section{VOCATIONAL CHOICE AND THE DRAMA OF ADOLESCENCE}

ABSTRACT: This paper, developed from a more extensive research that focused on the social imaginary concerning contemporary adolescence, investigates the concepts that future vocational advisers, psychology and pedagogy students, have on the adolescent who's preparing to choose a profession. The research was undertaken by using the Procedure of Thematic Story-Drawing and the analysis of data. Based on Bleger's concepts and a Winnicottian approach, data analysis disclosed the existence of the following non-conscientious psychological fields: doubt, parental desire and the lack of confidence in one's self. From a psycho-prophylactic perspective, the general picture indicates the need to rehabilitate the adolescent in re-appropriating his/her own destiny, since constant doubt appears as the consequence of not being able to trust in one owns ability nor in the decision making abilities of his/her parents, the outcome of various changes in the society that they belong to.

KEYWORDS: adolescence; social imaginary; vocational guidance; psychoanalysis; work.

\section{Introdução}

O trabalho é um fenômeno intrinsecamente dotado de grande complexidade. Considerado como conduta humana, vem acompanhando as notáveis mudanças da vida contemporânea e, consequentemente, vem sofrendo profundas modificações ao longo do último século.

Nas considerações que fazemos no presente estudo abordando o trabalho, assumimos a perspectiva blegeriana que considera conduta toda e qualquer manifestação humana, independente de suas variadas características (Bleger, 1963), podendo ser estudada pelos diversos campos das ciências humanas, a partir de suas perspectivas particulares. Poderíamos, assim, considerar uma psicologia do trabalho, uma psicopatologia do trabalho, uma sociologia do trabalho, uma antropologia do trabalho, uma história do trabalho, uma economia do trabalho, uma ética do trabalho, entre tantas outras. No presente artigo, consideraremos o trabalho como área fundamental do viver humano emocionalmente, focalizando especificamente a questão da escolha profissional.

Como já afirmamos, as concepções sobre o sentido e as formas do trabalho, enquanto conduta humana, têm va- riado enormemente no espaço e no tempo. Naquele que é, possivelmente, o livro mais lido no ocidente, a Bíblia, a questão do trabalho figura, logo nas primeiras páginas (Gênesis, 3,19), como um castigo e uma maldição divina: deverá o homem ganhar o pão com o suor do próprio rosto (Bíblia Sagrada, 1978, versão). Ao longo dos séculos, entre outras concepções, o trabalho vem sendo considerado desde uma atividade natural, que promove o desenvolvimento e a manutenção da saúde do homem, até uma mercadoria, uma atividade imposta pela sociedade, significando exclusivamente um gasto de energia física e mental e acarretando, dentre outras consequiências, as diversas doenças de que hoje temos notícias, como as lesões por esforço repetitivo - L.E.R. (Merlo et al., 2003), a Síndrome de Burnout, o stress ocupacional (Araújo, Aquino, Menezes, Santos \& Aguiar, 2003), a depressão (Dejours, 1987; França \& Rodrigues, 1997), dentre algumas das doenças decorrentes de condições outras do trabalho (Hallack \& Silva, 2005). Entre uma posição e outra, entre a saúde e a doença, encontramos inúmeras possibilidades de consideração do significado do trabalho na sociedade atual, como um produto social que sofre as alterações correspondentes na comunidade em que está inserido. 
Situamos o presente artigo referindo-nos a um grupo de pessoas que vivem num país que sofreu gravemente as consequiências de profundas modificações políticas, sociais, econômicas e tecnológicas. Um país que sobrevive a uma recessão econômica persistente nas últimas décadas e convive com o aumento do desemprego e dos subempregos (Guimarães, 2002; Urani, 1995) o que acarreta o comprometimento da saúde física e mental da população em idade produtiva (Ludermir, 2000). Abordamos, então, jovens na iminência de ingressarem num mercado de trabalho pouco atraente, que, sendo alunos de cursos que oferecem a disciplina Orientação Vocacional e Profissional, poderão orientar outros jovens para também ingressarem neste mesmo mercado, que apresenta entraves poderosos:

É verdade que a realidade se nos apresenta preocupante: altas taxas de desemprego, presença do desemprego estrutural, intensificação do ritmo de trabalho, crescimento do trabalho temporário e de tempo parcial, polarização em termos de qualificação e para os que permanecem no emprego a chamada "síndrome dos sobreviventes", angústia e medo, sentimentos que acompanham os não demitidos (Laranjeira, 2000, p. 14).

Ainda contextualizando, temos na formação escolar brasileira duas outras situações que corroboram e agravam as dificuldades encontradas pelos jovens que ingressam no mercado de trabalho brasileiro: os programas de aprovação escolar compulsória e os programas federais e estaduais de incentivo à formação superior, a exemplo do ProUni, Fies, Escola da Família.

Os programas de aprovação compulsória nas séries do ensino fundamental e médio, independente das ideologias que os sustentam, na prática têm se mostrado uma forma geradora de analfabetos funcionais. Encontramos, assim, nos cursos técnicos e na graduação, muitos alunos que, mesmo tendo passado pela fase da alfabetização propriamente dita e não encontrando dificuldade para decodificar signos lingüísticos, apresentam-se incapazes de estabelecer relações de sentido. Já os diversos programas de incentivo à formação superior que se apresentam ideológica e politicamente corretos uma vez que propõe a igualdade entre classes e a não discriminação dos menos favorecidos economicamente, compõem uma prática que se mostra perversa por alguns aspectos peculiares. Primeiro, porque quem tem direito a bolsas de estudo é o estudante cuja renda familiar seja inferior a um valor estabelecido, em geral muito baixo, e que tenha vindo de escolas públicas. Os estudantes cuja renda familiar ainda é baixa, mas não o bastante para justificar o recebimento da bolsa, e que vêm de escolas particulares, onde muitas vezes estudaram por receberem bolsas parciais, não conseguem o incentivo ficando, estes então, excluídos. Segundo, porque num país com muitas dificuldades educacionais, muitos dos jovens têm frequentemente uma educação básica deficitária, progredindo compulsoriamente conforme já apontamos quando nos referimos à progressão continuada, e, portanto, têm dificuldades de acompanhar uma graduação com maior grau de dificuldade, contribuindo para a diminuição da qualidade dos cursos de nível superior. As diversas graduações deixam, assim, de preparar profissionais capacitados e funcionam apenas como geradoras de diplomas. Além disso, o incentivo indiscriminado e sem a correspondente demanda no mercado de cursos de graduação proporciona a diminuição da importância das funções técnicas e a ilusão de que o mercado de trabalho absorve profissionais exclusivamente por possuírem um diploma de graduação. O resultado do que expusemos é encontrarmos nos bancos universitários jovens que não serão absorvidos pelo mercado nas funções que exigem nível superior e estarão superqualificados para as funções de nível técnico. Futuros desempregados.

Considerando tais dificuldades da parte de quem invariavelmente vai ser inserido no contexto citado, até mesmo por uma questão de sobrevivência, deparamo-nos, enquanto psicólogas e pesquisadoras, com a possibilidade e a necessidade de atuar preventivamente junto aos jovens que fazem parte desta realidade e farão parte do grupo de trabalhadores do país, o que julgamos poder ser feito através da orientação vocacional e profissional. ${ }^{1}$

As práticas atuais de orientação profissional no Brasil centram-se no indivíduo que escolhe, buscando auxiliar na escolha de uma profissão que concilie desejos pessoais e mercado de trabalho (Lisboa, 2002). Tais jovens advêm de regiões urbanas, de classe média e aspiram a uma profissão que tem formação superior. Considerando que tal indivíduo pertence a uma pequena parcela da sociedade brasileira, temos outros tantos jovens que aparentemente não têm oportunidade de escolha, pois precisam sobreviver, ou ajudar suas famílias a isso, trabalhando naquilo que lhes for oferecido.

Sabemos que as condições culturais incidem diferentemente na vivência individual e grupal conforme a classe social (Barus-Michel, 2005) e que as classes menos favorecidas têm as oportunidades de escolha diminuídas. No entanto, apesar de considerarmos importante a distinção entre classe média e classes sócio-economicamente desfavorecidas para compreendermos as especificidades dos diversos grupos que compõe a sociedade em que estão inseridos os jovens a que nos referimos neste trabalho, julgamos que, independente da classe, e de qualquer forma, uma possibilidade concreta de escolha sempre existe. Tal consideração refere-se à possibilidade de seguir outros caminhos, inclusive, o da marginalidade e da delinqüência onde, ao invés de trabalhar rouba-se, por exemplo. Assim, acreditamos que tais jovens também têm possibilidade, apesar de não terem muitas oportunidades, de escolha, e 
que um orientador vocacional poderá auxiliar no desenvolvimento de recursos internos que permitam ampliar as possibilidades destas escolhas. Mesmo sabendo da importância e da possibilidade de inúmeras considerações acerca de tais condições, neste artigo vamos nos referir àqueles jovens de quem já se espera, de antemão, que escolham uma profissão, lembrando que nem por isso têm uma vida mais fácil, porque as pressões que a classe média sofre também são muitas, principalmente por fazermos parte de um país em que se pauperiza muito rapidamente.

\section{A escolha profissional como parte da trajetória vital}

Partindo desta realidade, usamos, no presente trabalho a idéia amplamente discutida por Bleger (1963) da importância de se considerar as condições concretas na qual um fenômeno ocorre. Sendo a escolha profissional uma conduta humana, podemos dizer que o que se aplica às condutas, aplica-se também às escolhas. Assim, há que se considerar que, sendo influenciada por fatores pessoais e sociais, trata-se de uma manifestação vincular (AielloVaisberg \& Machado, 2000), o que a torna essencialmente ligada às condições concretas da existência destes adolescentes. Priorizando a concretude da experiência como base da pesquisa psicanalítica, Bleger (1963) a partir de Politzer (1929) enfatizou que a dramática humana é forjada na relação com o outro.

A escolha profissional interfere com o estilo de vida do jovem que escolhe e permeia tanto sua possibilidade de satisfação laboral como a de satisfação pessoal (Barreto, 2000), fazendo parte de sua relação concreta com a sociedade na qual está inserido e, nesta concepção, é parte da trajetória vital. Essa trajetória vital é compreendida, por nós, como drama do viver de adolescentes contemporâneos. Em coerência com o exposto, elegemos D. W. Winnicott (1967/1975) como interlocutor em nossas considerações justamente por ter formulado uma teoria que não se distancia do acontecer concreto (Aiello-Vaisberg, 1999) e estabelecemos como objetivo do presente artigo estudar a dramática do viver adolescente no que tange à escolha profissional.

Para compreendermos o imaginário de jovens em idade de escolha e praticando a docência em cursos de graduação que habilitam para a prática da orientação vocacional, optamos por uma pesquisa deste imaginário com os estudantes de tais cursos.

\section{Estratégias metodológicas}

Usamos como método o estudo do imaginário de um grupo especial, que tanto está próximo, em termos de trajetória pessoal de vida, da escolha, como também por ter escolhido, ele mesmo, cursar graduações que envolvem a orientação profissional. Assim, este grupo, composto por trinta e dois alunos de cursos de Psicologia e Pedagogia, constitui um meio que facilita o acesso ao imaginário coletivo e que nos comunica a concepção sobre o adolescente que escolhe.

Trata-se, pois, de um desenho metodológico qualitativo que busca compreender o imaginário do futuro orientador vocacional sobre a adolescência. Configuramos a pesquisa como um processo de investigação psicanalítica, durante o qual fazemos uso de associações livres e de atenção flutuante como aspectos constitutivos do método, transpondo-as, com os ajustes devidos, do consultório para a pesquisa. Apoiamo-nos no que Silva (1993, p. 20) destaca com clareza, adotando como nossa a concepção de que o método em psicanálise caracteriza-se:

\section{...por uma espécie de jogo em que fantasias de ambos os interlocutores organizam-se em busca de um con- senso sempre questionado a respeito do avesso do que foi dito. Ou seja, o método da psicanálise caracteriza- se por abertura, construção e participação.}

Ao nos referirmos ao imaginário de futuros orientadores vocacionais, explicitamos nossa intenção de abordar o imaginário coletivo do grupo que nos interessa conhecer enquanto representantes de uma coletividade, baseandonos na idéia de que o homem é um ser essencialmente social e considerando que cada pessoa expressa sua conduta tanto em âmbito individual quanto em âmbito coletivo (Bleger, 1963). Assim, do ponto de vista dramático podemos abordar a conduta humana a partir de sua singularidade, mas também, a partir dos coletivos aos quais pertence que, por sua vez, estão inseridos em um contexto maior social, cultural, histórico e político. $\mathrm{O}$ imaginário coletivo, nessa perspectiva, pode ser entendido como o lócus transicional que fundamenta e permeia as idéias, os sentimentos e as ações de uma pessoalidade coletiva. Usamos, dessa forma, o conceito de transicionalidade de Winnicott (1967/1975) que atribui ao lugar a que nos referimos o significado de espaço intermediário, ou transicional, entre o que é percebido objetivamente e concebido subjetivamente (Aiello-Vaisberg, 2004). Nesse espaço intermediário é que julgamos encontrar o real significado de pensamentos, sentimentos e ações humanos.

Realizamos a pesquisa nos anos de 2004 e 2005 quando, ao final de uma das aulas próximas do término do semestre, convidamos os alunos para participarem de uma atividade que se constituiria em uma pesquisa-interventiva. O objetivo do trabalho era duplo: subsidiar a produção de conhecimento sobre o imaginário daquele coletivo, e beneficiar os estudantes com um maior contato consigo mesmos, criando um recurso capaz de favorecer uma aprendizagem significativa, na qual aspectos cognitivos e afetivoemocionais pudessem se articular. Aqueles que não quisessem participar poderiam não fazê-lo, sem nenhum inconveniente. Todos os presentes nas salas mantiveram-se e participaram da atividade. 
Apesar de haver estudantes mais velhos, na faixa etária acima dos 40 anos, a maioria dos jovens que pesquisamos compõem uma pessoalidade coletiva com idade entre 20 e 25 anos, nascida no início dos anos oitenta, classe média/ baixa, nível cultural médio/baixo, cujas famílias vêm enfrentando problemas financeiros diversos oriundos de instabilidade econômica do país. Completaram a educação básica em escolas públicas e os que fazem o curso no período noturno trabalham para sustento próprio e os que fazem o curso no período matutino ainda dependem financeiramente da família. Estas informações servem à contextualização dramática dessa pessoalidade coletiva, uma vez que é preciso considerar a concretude, a historicidade e a socialização do grupo ao qual nos referimos nas pesquisas em psicanálise, como a que propomos (Aiello-Vaisberg, 2004, p. 197).

Para obtenção do material clínico, foram distribuídas folhas de sulfite A4 e foi solicitado aos alunos que desenhassem um(a) adolescente, da seguinte forma: "Desenhe um(a) adolescente em época de escolha profissional e, depois, escreva uma estória sobre ele(a), no verso da folha." Usamos, assim, o procedimento de Desenhos-Estórias com Tema, nos moldes desenvolvidos por Aiello-Vaisberg (2004) e por Trinca (1987) para investigação de imaginários coletivos, como recurso de abordagem para temas de difícil acesso, que não estão no campo consciente e/ou suscitam emoções indesejáveis. O uso de tal procedimento é coerente com uma análise psicanalítica, pensada como busca de campos psicológicos não conscientes e conseguida através da interpretação de sonhos, da associação livre, do uso da atenção flutuante, característicos da psicanálise clínica.

Considerando que um indivíduo que está vivendo sua conduta está impedido de conhecer o campo que a sustenta (Herrmann, 1991), o uso do procedimento de Desenhos-estórias com Tema facilita a expressão de determinações inconscientes e da dramática do viver humano. Este campo que permeia a conduta estabelece-se como uma matriz produtora de sentido (Aiello-Vaisberg, 1999).

Um campo, seja o da conversa, seja o de um jogo, seja o de qualquer relação humana, só é realmente visível quando não está em vigência; do contrário, esconde-se no avesso da relação sustentada. Se eu mantenho tal relação, seu campo é-me. Como percebê-lo? Pendurado no vazio, o campo de uma comunicação desvenda-se posteriormente em preconceitos, supostos gerais, omissões e negações... (Herrmann, 1991, p. 108).

Assim, no procedimento que adotamos, ao considerarmos os desenhos-estórias dos estudantes, encontramos os seguintes campos a partir dos quais os estudantes pensam a escolha profissional do adolescente: "ser ou não ser", "tudo que seu mestre mandar" e "estou pronto"?

O campo da indecisão é o mais freqüente e se manifesta nas produções em que o jovem aparece ansioso, oscilando entre vários caminhos, ora muito infantilizado ora extremamente angustiado frente à tarefa de integrar desejos que encara como opostos. Nas palavras de uma aluna: "Essa adolescente está no seu inferno astral, na

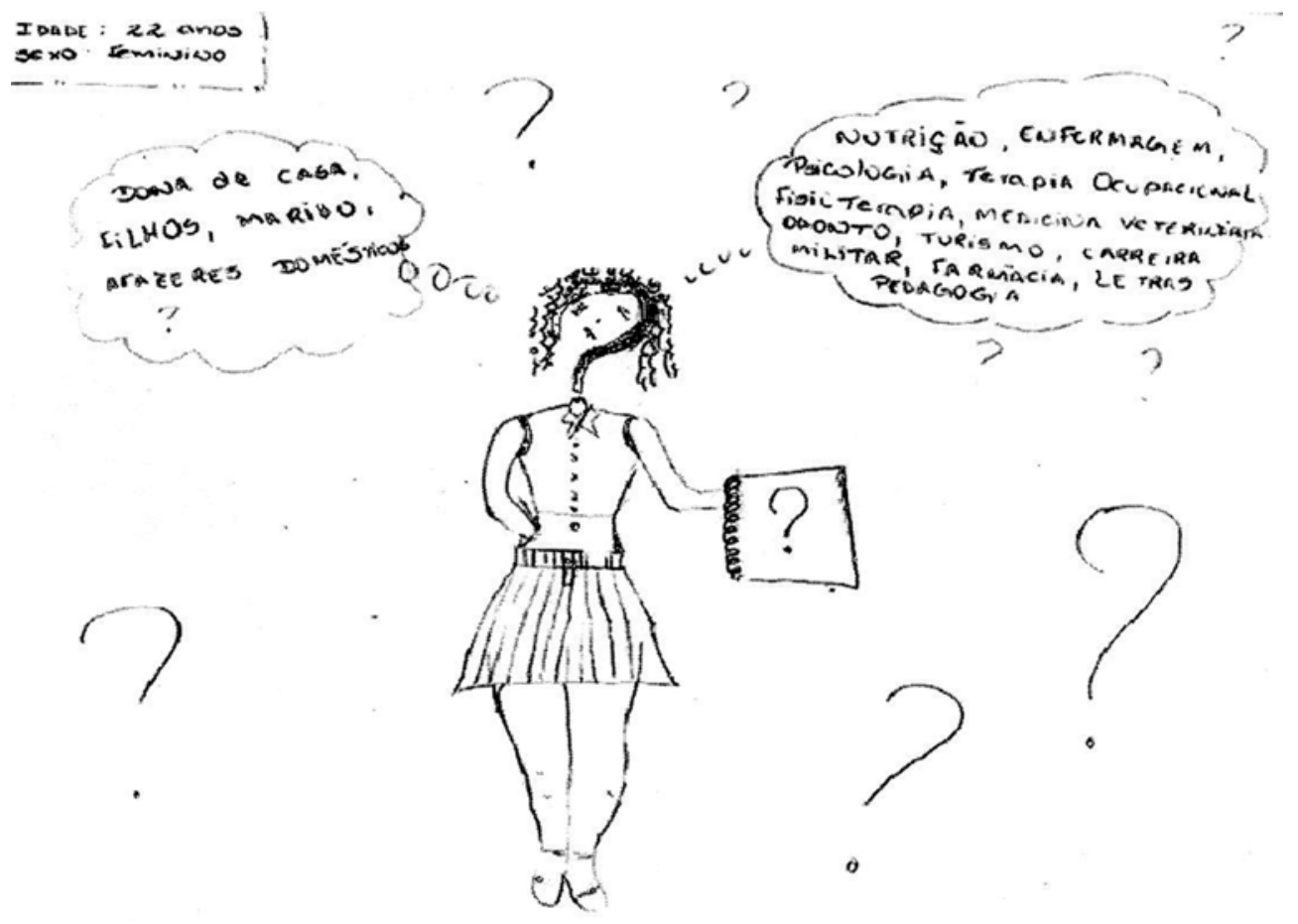

Figura 1. Ser ou não ser? 
maior crise, pois escolher ou optar por alguma profissão é horrível...” Aparecem, então, desenhos em que o jovem oscila entre ser jogador de futebol porque gosta e ter muito dinheiro com uma profissão que não gosta, ou ter filhos e marido e cursar uma faculdade, por exemplo.

É interessante apontar que não se referem em nenhum momento aos casos de jovens que já decidiram a própria carreira, apontando o adolescente sempre à mercê do destino, quase como se adolescência e sorte fossem sinônimos. Desconsideram, inclusive, um fenômeno muito comum: o da idealização rígida em torno de uma única profissão, como nos muitos casos atendidos em consultório, de filhos ou parentes de médicos que decidem seguir a profissão já na infância. Quando aparecem as profissões idealizadas, aparecem, também agrupadas, formando quase que uma totalidade: a das melhores profissões, o que também provoca dúvida já que não dá para fazer Engenharia, Medicina e Direito, ao mesmo tempo. Paralelamente, destacamos que mesmo em se tratando de grupos de classe média/baixa, como indicamos anteriormente, cuja inserção mais rápida no mercado de trabalho se faria por um curso técnico ou tecnológico, essa opção não é sequer considerada. Em trabalho paralelo de supervisão de estágio destes mesmos alunos, na prática da orientação vocacional com jovens em escolas públicas, percebemos o que foi confirmado neste grupo pesquisado: apesar de mais comuns em cidades do interior do que cursos de graduação, os cursos técnicos não aparecem no imaginário dos jovens como possibilidade desejada de inserção no mercado de trabalho. Quando aparecem, acontece por falta de opção. Isso sugere que paira o preconceito de que o diploma de graduação é sinônimo de sucesso profissional, por si só. Estendendo tal fenômeno para nossa realidade educacional, encontramos aqui uma das razões para o número cada vez maior de jovens graduados desempregados, pois o mercado não acompanha a oferta dessa mão de obra que se forma a qualquer custo e, muitas vezes, sai despreparada.

O campo do desejo parental é representado nas produções que expressam claramente tendências a adotar profissões tradicionais, como resposta a uma necessidade ou expectativa dos pais, aparecendo nas estórias como coloca o aluno:

...Joãozinho, então com 17 anos, precisa decidir [sobre] o que escolher para fazer durante o resto de sua vida. Gosta de matemática, então pensa em fazer Engenharia, mas também adora participar do jornalzinho de sua escola, escrevendo artigos. E tem também as aulas de violão que João adora; até pensou em seguir a carreira de músico, a qual seus pais não concordam, pois, segundo eles, não traz retorno financeiro.

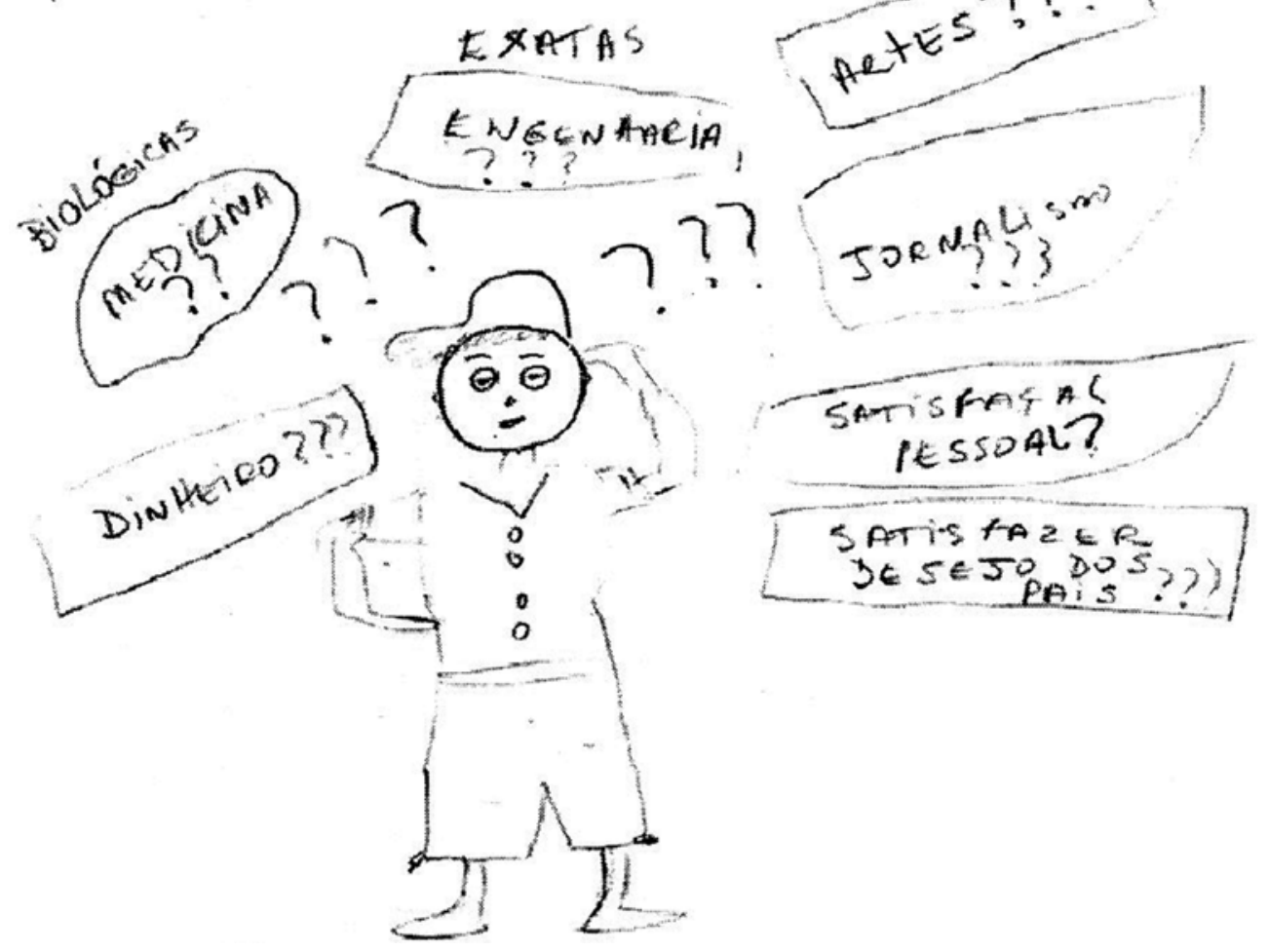

Figura 2. Tudo que seu mestre mandar. 
Tais profissões, a saber: Engenharia, Medicina, Direito são as que os pais, consideram, ainda, mais respeitáveis e rentáveis, do ponto de vista dos alunos e das expectativas coletadas em consultório em entrevistas com pais de adolescentes em processo de orientação vocacional, e são colocadas como uma real possibilidade pelos jovens, mesmo que isso signifique abrir mão ou adiar os próprios sonhos. Considerando que a presente pesquisa foi feita com alunos de Psicologia e Pedagogia, os mesmos se enquadram dentre aqueles tantos que optaram por uma profissão situada em condições inferiores e menos respeitáveis que as tradicionais, o que é demonstrado nos desenhosestórias como um conflito que eles mesmos vivenciaram. Lembramo-nos dos preconceitos enfrentados bravamente por um rapaz que procurou orientação profissional em clínica particular. Estando na iminência de uma depressão, era filho de pais continentes, que o apoiavam nas decisões em geral e se mostravam bastante preocupados com a felicidade do filho. Freqüentava uma universidade estadual muito conceituada, na qual ingressou após um único vestibular, tendo escolhido o curso supostamente por uma preferência nas brincadeiras de infância, a qual os pais incentivavam por julgarem que o filho tinha as habilidades necessárias. Então no $3^{\circ}$ ano, estava completamente desmotivado, encontrava dificuldades em diversas disciplinas e a reprovação já era iminente. Após orientação voca- cional, resolve enfrentar a todos e a si mesmo e cursar uma graduação cujo desdobramento no mercado de trabalho era a carreira acadêmica, também numa faculdade estadual conceituadíssima, deparando-se, pela primeira vez, com a oposição do pai que tinha uma profissão das mais tradicionais...

O campo da falta de confiança em si é comunicado por situações em que o adolescente está inseguro e ansioso por sentir-se despreparado para a entrada na vida adulta. Tal passagem tem como marca justamente a escolha profissional, e se mostra mais difícil pelo jovem não possuir objetivos definidos e também por considerar os próprios desejos como menos importantes no mundo adulto, numa dissociação entre prazer e dever. Aparece em produções como a do aluno que escreve:

Era uma vez um adolescente que gostava muito de ficar o dia todo na rua com os amigos, pensar em roupas, sapatos... ouvir música... ir para festas, bares $e$ danceterias e amanhecer.. paquerar.. namorar $o$ dia inteiro... e odiava a escola, professor e a imposição de ter que estudar.. ter um diploma como único objetivo de vida!!

Lembramo-nos de adolescentes interioranos dos anos 70 que priorizavam sair de casa para se tornarem independentes e vemos os adolescentes atuais, amedrontados pelas

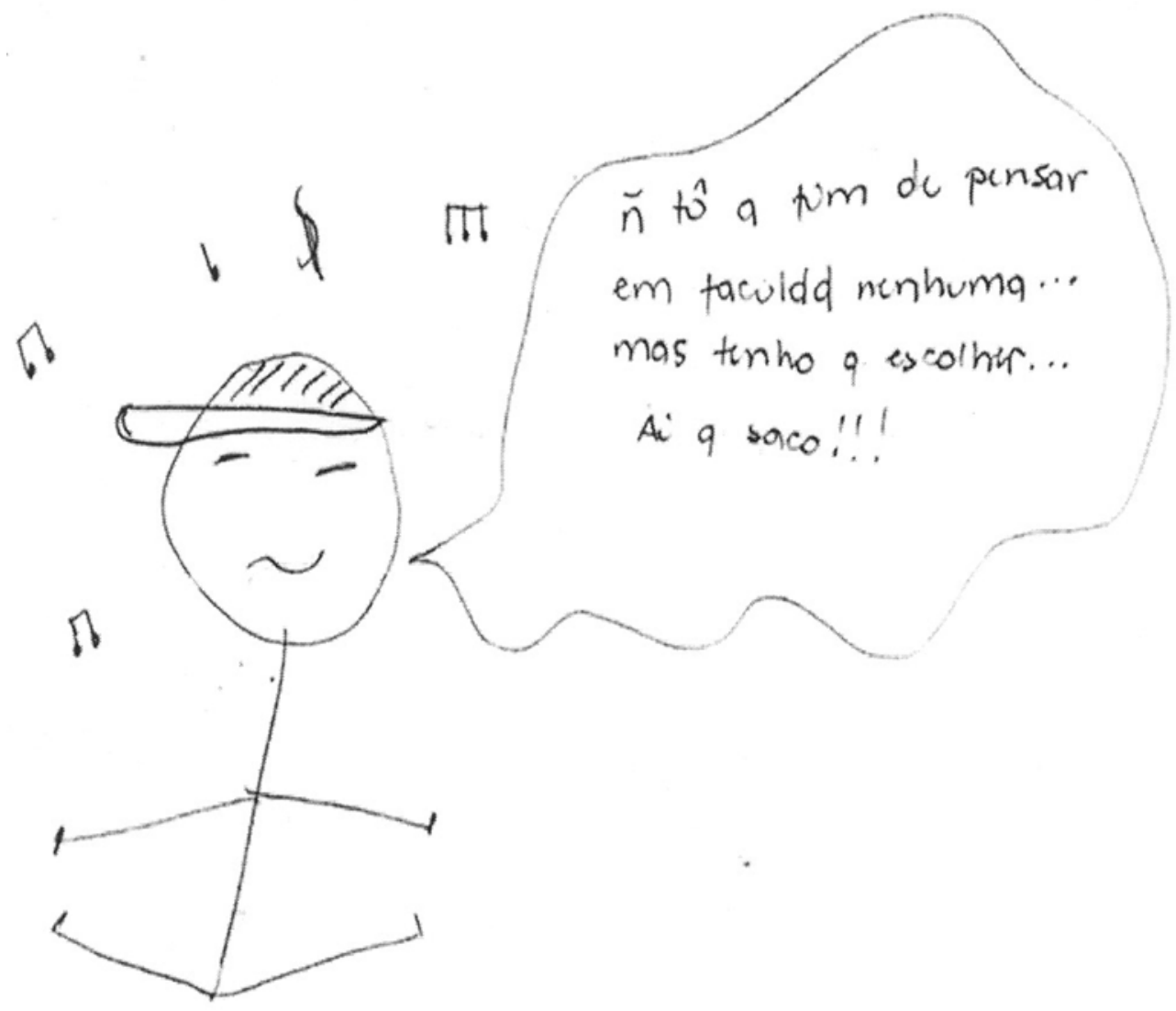

Figura 3. Estou pronto? 
incertezas tão alardeadas pela mídia e corroboradas pelos pais, pelas dificuldades financeiras enfrentadas pela maioria dos adultos com os quais têm contato e pelo medo familiar de prejuízos futuros na vida adulta do filho que, no imaginário, superam os benefícios. Tais prejuízos englobam, como aparece frequentemente nas consultas de orientação vocacional com os pais dos adolescentes, desde sofrer violência física direta ou indiretamente, como as brigas de trânsito, ou mesmo balas perdidas, passando pelo envolvimento com pessoas que não conhecem e possam ser "más companhias", até chegar no uso e abuso de drogas, na promiscuidade sexual, entre outros, como se o jovem de hoje estivesse mais exposto e menos preparado para enfrentar os perigos inevitáveis que a vida oferece.

\section{Considerações sobre os Campos Desvelados}

Permeando os três campos está sempre, como pano de fundo, a insegurança concreta da vida cotidiana. Nossos jovens são criados atualmente de forma diferente do modo mais tradicional, que já dava responsabilidades paulatinamente, não ocasionando uma grande diferença entre a infância e a adolescência. A prática atual parece realmente estabelecer uma divisão drástica entre mundo infantil e adulto, contribuindo para o medo do futuro e para a dificuldade do estabelecimento de metas.

Voltando tal prática para a questão da escolha profissional, podemos observar que, antigamente, era natural que os pais escolhessem a profissão para os filhos, o desejo paterno era entendido como caminho natural e seguro para a escolha profissional: eram os pais quem diziam quem seria padre, quem estudaria, e se estudaria direito ou medicina. Hoje é fundamental acompanharmos o avanço da liberdade individual. Se, antigamente, tínhamos algumas dezenas de profissões possíveis entre aquelas que exigiam cursos de nível médio e superior, hoje temos mais de uma centena de cursos de graduação, além das especializações possíveis que demandam novas escolhas e oferecem novas possibilidades.

Indubitavelmente o aumento das oportunidades de escolha ampliou a possibilidade do homem exercer seu potencial criativo, mas trouxe consigo inúmeras outras dificuldades, ainda mais pelo fato dos pais não terem acompanhado tais mudanças e, assim, não prepararem seus filhos para elas. Dessa forma, parece haver uma retro alimentação das angústias que, sendo paternas afetam diretamente aos filhos que, assumindo-as como suas, afetam diretamente aos pais.

Parece-nos ser essa uma das questões centrais da adolescência contemporânea e a principal na consideração da escolha profissional como parte da trajetória vital: qual a real contribuição que o mundo adulto, representado pelos pais, mas também pela sociedade em geral, oferece atualmente para o incentivo e a preparação de nossos jovens?
O quadro que se apresenta denuncia frequentemente a dúvida como resultado do não poder confiar em suas próprias capacidades nem nas capacidades decisórias dos pais. Além disso, o mundo contemporâneo é todo cheio de dúvidas: as grandes narrativas totalizadoras, religiosas ou políticas, perderam força nas últimas décadas e os indivíduos não contam, em nenhuma área, com prescrições bem definidas acerca do que é melhor: adaptar-se ao modus vivendi estabelecido, transformá-lo ou propor novos projetos para o mundo. Então, em quem confiar?

Num panorama como esse, a escolha profissional perde seu significado. Deixa de ser uma real possibilidade de concretização de um percurso humano determinado sóciohistoricamente, mas único já que individualizado e autônomo e insere-se como uma possibilidade irreal. Irreal no sentido de falsa, já que muitas vezes se engana quem escolhe ao ter a sensação de que foi o agente da escolha, quando, na verdade, foi escolhido pelo sistema. Nos moldes blegerianos, sendo todos produtores mas também produtos da vida social, muitas vezes nos iludimos com uma suposta liberdade para as escolhas que fazemos, o que supostamente impediria a espontaneidade. No entanto, pensando a espontaneidade como algo que não se faz abstraidamente das condições concretas de vida, concordamos com Winnicott (1967/1975) quando aponta a importância da escolha não submissa, da escolha que se faz a partir do ser, da escolha de um fazer que seja "ser e fazer", isto é, que se funde no estilo de cada um.

Pensando psicoprofilaticamente, cremos ser interessante e necessária a tentativa de reabilitação do jovem na reapropriação de seu destino, que estará tanto mais saudável quanto mais sentir-se vivo, real e capaz de uma escolha configurada pela gestualidade espontânea e transformadora do próprio mundo.

\section{Notas}

1 Existe, na literatura sobre o assunto, uma divergência quanto ao uso dos termos vocacional e profissional. Apesar do termo vocação ser usado tradicionalmente dentro de uma visão determinista e o termo profissional ser usado na referência às mudanças sócioculturais às quais as profissões estão sujeitas, a maioria dos autores usa os dois como sinônimos. Preferimos "Orientação Profissional" por se tratar da inserção num mercado que estabelece "profissões". Usamos o termo vocação para aspectos mais subjetivos, voltados àquilo que é menos “mensurável”, não necessariamente ligado a desempenho. No presente texto, usamos os dois como sinônimos, destacando o "profissional" apenas quando nos referimos a mercado de trabalho e orientação vocacional e profissional quando nos referimos aos aspectos mais subjetivos da escolha.

\section{Referências}

Aiello-Vaisberg, T. M. J. (1999) Encontro com a loucura: Transicionalidade e ensino de Psicopatologia. Tese de Livre-Docência 
não-publicada, Universidade de São Paulo, Instituto de Psicologia, SP.

Aiello-Vaisberg, T. M. J. (2004). Ser e fazer: Enquadres diferenciados na clínica winnicottiana. São Paulo, SP: Idéías \& Letras.

Aiello-Vaisberg, T. M. J., \& Machado, M. C. L. (2000). Diagnóstico estrutural da personalidade em Psicopatologia Psicanalítica. Psicologia USP, São Paulo, 11(1), 29-48.

Araújo, T. M., Aquino, E., Menezes, G., Santos, C. O., \& Aguiar, L. (2003, ago.) Aspectos psicossociais do trabalho e distúrbios psíquicos entre trabalhadoras de enfermagem. Revista de Saúde Pública, 37(4). Retirado em 26 ago. 2006, da Base de dados SciELO (Scientific Electronic Library On line).

Barreto, M. A. M. (2000, nov.). A importância de uma escolha profissional adequada para a realização pessoal dos indivíduos: Algumas considerações. Revista Ciências da Educação, 2(3), 177-185.

Barus-Michel, J. (2005). Entre sofrimento e violência: A produção social da adolescência. In: Anais Eletrônicos... Simpósio Internacional do Adolescente, 1, 2005, São Paulo. Recuperado em 04 jun. 2006, da Base de dados SciELO.

Bíblia Sagrada. (1978). (26. ed.). São Paulo, SP: Ave-Maria.

Bleger, J. (1963). Psicologia de la conduta. Buenos Aires, Argentina: Paidós.

Dejours, C. (1987). A loucura do trabalho: Estudo de Psicopatologia do trabalho. São Paulo, SP: Oboré.

França, A. C. L., \& Rodrigues, A. L. (1997). Stress e trabalho: Guia básico com abordagem psicossomática. São Paulo, SP: Atlas.

Guimarães, N. A. (2002, out.). Por uma sociologia do desemprego. Revista Brasileira de Ciências Sociais, 17(50), 104-121.

Hallack, F. S., \& Silva, C. O. da. (2005). A reclamação nas organizações do trabalho: Estratégia defensiva e evocação do sofrimento. Psicologia \& Sociedade, 17(3). Retirado em 20 ago. 2006, da Base de dados SciELO.

Herrmann, F. (1991). Clínica psicanalítica: A arte da interpretação. São Paulo, SP: Brasiliense.

Laranjeira, S. M. G. (2000, jul./dez.). As transformações do trabalho num mundo globalizado. Sociologias, 4, 14-19.

Lisboa, M. D. (2002). Orientação profissional e mundo do trabalho. In R. S. Levenfus (Ed.), Orientação vocacional ocupacional: Novos achados teóricos, técnicos e instrumentais para a clínica, a escola e a empresa. Porto Alegre, RS: Artmed.

Ludermir, A. B. (2000, jul./set.). Inserção produtiva, gênero e saúde mental. Cadernos de Saúde Pública, 16(3), 647-659.
Merlo, A. R. C., Vaz, M. A., Spode, C. B., Elbern, J. L. G., Karkow, A. R. M., \& Vieira, P. R. de B. (2003). O trabalho entre prazer, sofrimento e adoecimento: A realidade dos portadores de lesões por esforços repetitivos. Psicologia \& Sociedade, 15(1). Retirado em 27 ago. 2006, da Base de dados SciELO.

Politzer, G. (1929). Crítica de los fundamentos de la Psicologia. Madrid, España: Nueva Biblioteca.

Silva, M. E. L. (1993). Pensar em Psicanálise. In M. E. L. da Silva (Ed.), Investigação e Psicanálise (pp. 11-25). Campinas, SP: Papirus.

Trinca, W. (1987). Investigação clínica da personalidade - Odesenho livre como estímulo da percepção temática. São Paulo, SP: EPU.

Urani, A. (1995). Crescimento e geração de emprego e renda no Brasil. Lua Nova - Revista de Cultura e Política, 35, 5-37.

Winnicott, D. W. (1975). A localização da experiência cultural. In D.W. Winnicott. O Brincar e a realidade (pp. 133-143). Rio de Janeiro, RJ: Imago. (Original publicado em 1967)

Maria Auxiliadora Barreto é psicóloga clínica, mestre em Educação pelo Centro Universitário Salesiano de São Paulo - UNISAL. Doutora em Psicologia como Profissão e Ciência pela Pontifícia Universidade Católica de Campinas PUC/CAMP. Professora universitária da PUC/CAMP. Endereço para correspondência: Rua Hepacaré, 237 - Lorena - SP. CEP 12600-340.

maria.barreto@uol.com.br

Tania Aiello-Vaisberg é psicóloga clínica, professora livre docente e orientadora do Programa de Pós-Graduação da PUCCAMP. tanielo@uol.com.br

\section{Escolha profissional e dramática do viver adolescente}

Maria Auxiliadora Barreto e Tania Aiello-Vaisberg

Recebido: 31/08/2006

$1^{\text {a }}$ revisão: 08/11/2006

Aceite final: 28/11/2006 